\title{
Wall Synthesis and Assembly During Hyphal Morphogenesis in Schizophyllum commune
}

\author{
By J. G. H. WESSELS, J. H. SIETSMA* AND A. S. M. SONNENBERG \\ Department of Developmental Plant Biology, Biological Centre, University of Groningen, Haren, \\ The Netherlands
}

(Received 22 November 1982)

\begin{abstract}
Pulse-chase experiments with $\left[{ }^{14} \mathrm{C}\right]$ glucose suggested that in growing hyphae of Schizophyllum commune, a water-soluble $\beta$-glucan is a precursor for the alkali-insoluble chitin- $\beta$-glucan complex in the wall. With microautoradiography it was found that this complex was not present at the very tip of the growing hyphae where chitin and $\beta$-glucan were inserted into the wall as individual polymers. The two polymers were then gradually turned into an insoluble complex, probably by covalent cross-linking. This was also observed in the entire hyphal apex after arrestment of growth. Evidence is presented which indicates that complex formation affects the mechanical properties of the wall, and a model is given in which the formation of a complex between chitin and $\beta$-glucan accounts for the change from plasticity towards rigidity of the wall during hyphal morphogenesis.
\end{abstract}

\section{INTRODUCTION}

As a rule, fungal hyphae elongate by apical extension. This exemplifies a simple morphogenetic system in which wall expansion and wall synthesis occur at an apical zone of limited size while a rigid cylinder of wall material is produced that does not yield to the turgor pressure.

Theoretical considerations (Green, 1974; Trinci \& Saunders, 1977; Koch, 1982) have made it clear that wall expansion is maximal at the extreme tip and declines towards zero at the base of the extension zone according to a predictable gradient dependent on the shape of the apical dome. With turgor pressure as the driving force, this implies that the decline in expansion is caused by a decrease in the tendency of the wall to yield to the turgor pressure. Because the thickness of the wall remains uniform during expansion (Trinci \& Collinge, 1975), expansion rate as a function of the plasticity of the wall and addition of new wall materials must decline along a similar gradient from the extreme tip to the base of the extension zone. Indeed, precise measurements of the distribution of chitin synthesis in the extension zone of Neurospora crassa hyphae have shown the validity of these concepts (Gooday \& Trinci, 1980; Koch, 1982).

The correlation between wall synthesis and wall plasticity has been a matter of much speculation. One model, advanced by Bartnicki-Garcia (1973) and widely accepted in the literature, considers that the apex is unable to expand until loosened by hydrolytic enzymes. Such lysins would cause breaks in existing polysaccharide chains, producing loci at which insertion of new chains by biosynthetic enzymes occurs. Another model can be based on the assumption that the new wall material laid down at the apex is initially plastic but is gradually turned into a more rigid material (Robertson, 1968).

In the fungi belonging to the ascomycetes and basidiomycetes, chitin and $(1 \rightarrow 3)-\beta /(1 \rightarrow 6)-\beta-D-$ glucan are ubiquitous components of the wall (Wessels \& Sietsma, 1981). Although both components may occur independently, at least some of the chitin and $\beta$-glucan chains appear covalently linked, producing an alkali-insoluble complex (Sietsma \& Wessels, 1979, 1981). In Schizophyllum commune, for example, all of the $\beta$-glucan in the wall appears to be rendered 
insoluble by covalent linkages to chitin chains. Work with regenerating protoplasts of $S$. commune has revealed that at least $(1 \rightarrow 3)$ - $\beta$-glucan is synthesized as a hot-water-soluble polymer that is subsequently rendered alkali-insoluble by linkage to chitin, apparently by enzymes that reside in the wall (Sonnenberg et al., 1982). Such cross-linking may produce a rigid wall structure and the wall may be relatively plastic as long as the two components occur in the wall as separate polymers. Such a mechanism, if also occurring at the hyphal apex, would be highly relevant for explaining the correlation between the gradients of wall synthesis and wall plasticity that determine hyphal morphogenesis. The present study shows that the alkali-insoluble glucan is indeed synthesized at the very tip as a hot-water-soluble glucan and only gradually turned into an insoluble complex.

\section{METHODS}

Growth of mycelium. Dikaryotic mycelium of $S$. commune, obtained by mating strains 1-40 (CBS 344.81) and 1-50 (CBS 342.81), was grown on minimal medium (Dons et al., 1979) supplemented with $15 \mathrm{~g}$ agar $1^{-1}$ at $24^{\circ} \mathrm{C}$ in Petri dishes placed upside down. Basidiospores from fruit bodies accumulating on the lids were collected regularly and stored in portions at $-40^{\circ} \mathrm{C}$ in sterile water. When needed, a portion was thawed and used to inoculate liquid minimal medium $\left(8 \times 10^{7}\right.$ basidiospores $\left.\mathrm{ml}^{-1}\right)$ containing $5 \mathrm{mg}$ glucose $\mathrm{ml}^{-1}$. Incubation of these cultures at $24^{\circ} \mathrm{C}$ on a rotary shaker (150 r.p.m.) for $16 \mathrm{~h}$ resulted in hyphae with few branches and with an average length of $56 \mu \mathrm{m}$.

Radioactive labelling of the mycelium. After $16 \mathrm{~h}$ growth the hyphae were labelled by adding $\left[\mathrm{U}-{ }^{14} \mathrm{C}\right]$ glucose $\left(150 \mathrm{mCi} \mathrm{mmol}^{-1} ; 1 \mathrm{mCi}=37 \mathrm{MBq}\right),\left[6{ }^{-3} \mathrm{H}\right] \mathrm{glucose}\left(25 \mathrm{Ci} \mathrm{mmol}^{-1}\right), N$-acetyl[1 $\left.{ }^{-14} \mathrm{C}\right] \mathrm{glucosamine}(50 \mathrm{mCi}$ $\mathrm{mmol}^{-1}$ ), or $\mathrm{N}$-acetyl[6-3 $\left.\mathrm{H}\right] \mathrm{glucosamine}\left(5 \mathrm{Ci} \mathrm{mmol}^{-1}\right)$ (all obtained from New England Nuclear) for various periods. Radioactivity in the medium was then chased by filtering off and washing the hyphae on glass-fibre discs, which were never allowed to run dry. Washing and resuspension to the original concentration were done in spent medium, after removal of hyphae, from an unlabelled parallel culture. In the case of labelling with radioactive $N$-acetylglucosamine, $0.45 \mathrm{mM}$ cold $N$-acetylglucosamine was added to the spent medium. The whole chase procedure took about $3 \mathrm{~min}$.

Distribution of label between the different glucan fractions. Radioactive glucose labelled all cell constituents. To determine the amount of radioactivity present specifically in the glucans, without having to resort to rigorous purification procedures, a method was developed in which both the total glucan in the fractions and the specific radioactivity of glucose in hydrolysates of the fractions was determined. Samples taken from cultures labelled with [U-1 ${ }^{14} \mathrm{C}$ ]glucose $\left(50 \mu \mathrm{Ci} \mathrm{ml}^{-1}\right)$ were immediately frozen in liquid nitrogen, passed through an $\mathrm{X}$-press (Biotec, Sweden) and the frozen disrupted material was collected in 2 volumes of methanol at $60^{\circ} \mathrm{C}$. After thorough mixing, the suspension was centrifuged at $3000 \mathrm{~g}$. The pellet was washed three times with $66 \%(\mathrm{v} / \mathrm{v})$ methanol and protein was digested by pronase (Calbiochem; $1 \mathrm{mg} \mathrm{ml}^{-1}$ in $0.01 \mathrm{M}$-phosphate buffer $\mathrm{pH} 7.5$ ) at $35^{\circ} \mathrm{C}$ for $18 \mathrm{~h}$ under toluene. Subsequently, the digest was heated at $100^{\circ} \mathrm{C}$ for $1 \mathrm{~h}$ to solubilize water-soluble glucans. The

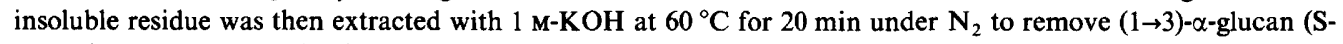
glucan) and any other alkali-soluble glucans.

The materials left after methanol extraction (total glucan), after hot-water extraction (water-soluble glucans removed), after alkali-extraction (alkali-soluble glucans removed), and the final residue (alkali-insoluble glucan) were all resuspended in $1 \mathrm{M}-\mathrm{HCl}$. A sample was taken to determine the total glucan content with the anthrone reagent (Fairbairn, 1953) and the rest was hydrolysed at $120^{\circ} \mathrm{C}$ for $2 \mathrm{~h}$. The hydrolysate was dried in vacuo above $\mathrm{KOH}$ pellets and $\mathrm{P}_{2} \mathrm{O}_{5}$, dissolved in water and spotted on a thin-layer cellulose plate and chromatographed in pyridine/ethyl acetate/acetic acid/water $(5: 5: 1: 3$, by vol.). The glucose was located by scanning for radioactivity with a Berthold scanner, then scraped from the plate and extracted with water. The radioactivity in the eluate was measured by the liquid scintillation method and the glucose content was determined enzymically using glucose oxidase (the GOD-PAP test; Boehringer). In this way the specific radioactivity of the glucan could be calculated, while the total radioactivity in the glucan followed from the known glucan content of the fractions and the specific radioactivity.

Autoradiography. Disruption of hyphae with an X-press leads to a loss of most of the radioactivity at the hyphal apex (see Results). In addition, the method described above does not allow specific removal of the water-soluble glucan. Therefore, for autoradiography the non-polysaccharide cell constituents were removed from intact hyphae by extraction with $1 \mathrm{M}-\mathrm{KOH}$ in $66 \%(\mathrm{v} / \mathrm{v})$ ethanol.

Hyphae $(16 \mathrm{~h})$ were labelled for 10 min with either $\left[6{ }^{3} \mathrm{H}\right] \mathrm{glucose}\left(100 \mu \mathrm{Ci} \mathrm{ml}^{-1}\right)$ or $N$-acetyl[6- $\left.{ }^{3} \mathrm{H}\right] \mathrm{glucosamine}$ $\left(50 \mu \mathrm{Ci} \mathrm{ml}^{-1}\right)$ and then the radioactivity was chased for 15 or $45 \mathrm{~min}$, respectively. Samples were taken from the cultures and growth stopped by addition of two volumes of methanol. The hyphae were washed with $66 \%$ methanol and once with $66 \%$ ethanol. The cytoplasm was then extracted with a $1 \mathrm{M}-\mathrm{KOH} /$ ethanol mixture $(1: 2$, $\mathrm{v} / \mathrm{v})$ at $60{ }^{\circ} \mathrm{C}$ for $15 \mathrm{~min}$. The residue was washed with $66 \%$ ethanol and it represented the total-wall fraction. It was subsequently extracted with water at $100^{\circ} \mathrm{C}$ for $1 \mathrm{~h}$ (water-soluble glucan removed) and with $1 \mathrm{M}-\mathrm{KOH}$ at 


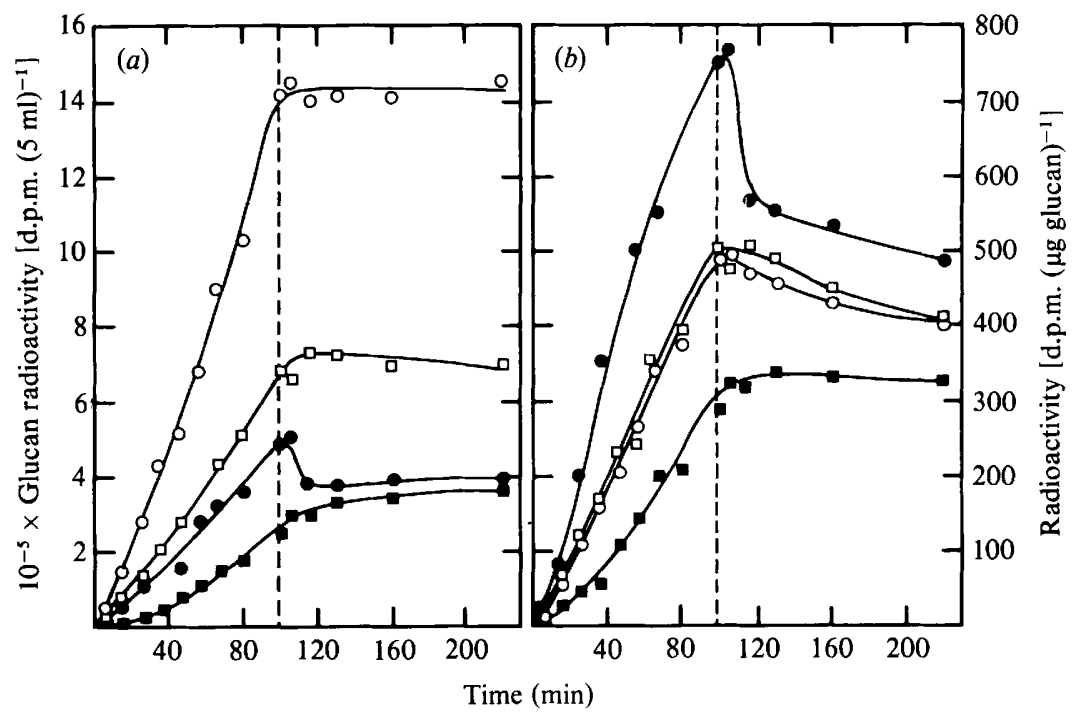

Fig. 1. Incorporation of $\left[\mathrm{U}^{-14} \mathrm{C}\right]$ glucose into different glucans of the mycelium of $S$. commune. Minimal medium ( $80 \mathrm{ml}$, containing $5 \mathrm{mg}$ glucose $\mathrm{ml}^{-1}$ ) was inoculated with $6 \times 10^{9}$ basidiospores. After $16 \mathrm{~h}$ growth, at which time $1.25 \mathrm{mg}$ glucose $\mathrm{ml}^{-1}$ was still present, a pulse of $4 \mathrm{mCi}$ [U-1 ${ }^{4} \mathrm{C}$ ]glucose was given for $100 \mathrm{~min}$. The radioactivity was then chased (see Methods) and incubation continued in nonradioactive minimal medium. Samples of $5 \mathrm{ml}$ were taken at the times indicated, and were immediately frozen in liquid nitrogen and stored at $-80^{\circ} \mathrm{C}$ until all samples were collected. Samples were processed and extracted as described in Methods and the total amount and specific radioactivity of the glucan was estimated in each fraction. (a) Total radioactivity, and $(b)$ specific radioactivity in the different glucan fractions. Incorporation of label in: total glucan (O), hot-water-soluble glucan (O), $1 \mathrm{M}-\mathrm{KOH}$-soluble glucan ( $\square$ ), and $1 \mathrm{M}-\mathrm{KOH}$-insoluble glucan ( $\square$ ).

$60^{\circ} \mathrm{C}$ for $20 \mathrm{~min}$ (alkali-soluble glucan removed). Finally, the residue was incubated overnight with exo-( $\left.1 \rightarrow 3\right)-\beta$ glucanase as described previously (Sonnenberg et al., 1982). After each extraction a sample was taken and spread on microscope slides coated with gelatin chrome alum (Rogers, 1969). After drying, the slides were covered with Kodak AR-10 stripping film, packed in light-tight boxes, exposed at $4{ }^{\circ} \mathrm{C}$ for 2 to $5 \mathrm{~d}$, and then developed in Kodak D19 developer and fixed. Grains were counted at a magnification of $\times 1000$ in measured segments $(0.6 \mu \mathrm{m})$ with a Wild phase-contrast microscope using an eyepiece micrometer.

Fragmentation of hyphae. Hyphae were fragmented by passing a suspension of mycelium in water through an Xpress at $-25^{\circ} \mathrm{C}$ to $-30^{\circ} \mathrm{C}$ and a pressure of about $5000 \mathrm{~kg} \mathrm{~cm}^{-2}$.

\section{RESULTS}

Water-soluble glucan as precursor for alkali-insoluble glucan

To obtain precise information about the flow of carbon into different glucan fractions during hyphal growth, actively growing germlings of $S$. commune basidiospores ( $16 \mathrm{~h}$ cultures; average hyphal growth rate $3.68 \mu \mathrm{m} \mathrm{h}^{-1}$ ) were subjected to a pulse-chase treatment with $\left[{ }^{14} \mathrm{C}\right] \mathrm{glucose}$. Samples were taken at various times and both the specific radioactivity and the absolute radioactivity in the glucan fractions was determined as described in Methods. It should be emphasized that, regardless of contamination of the glucan fractions with other components, the employed procedure gives data pertaining only to the glucan in these fractions. The results of such an experiment, in which the hyphae were continuously labelled for $100 \mathrm{~min}$ and subsequently grown in a non-radioactive medium, are given in Fig. 1.

The results in Fig. 1 (a) show that for total glucan there was an almost linear increase in radioactivity during the labelling period and that radioactivity was not lost during the chase. Apparently, in these actively growing cultures glucan is metabolically stable. However, examination of the flow of radioactivity into the separate glucan fractions revealed a more complicated pattern. In particular, the incorporation of label into the alkali-insoluble glucan 
fraction lagged behind, and during the chase period the radioactivity of this fraction increased by about $30 \%$. At the same time there was a rapid drop in the radioactivity of the water-soluble glucan fraction and a slower and less conspicuous drop in the radioactivity of the alkali-soluble glucan fraction. The kinetics of labelling after the chase suggest that radioactivity from the water-soluble glucan fraction was transferred, possibly through the alkali-soluble glucan fraction, into the alkali-insoluble glucan fraction. The differences in the labelling pattern of the glucan fraction are also clearly visible when the specific radioactivity of the fractions is examined (Fig. 1b). During labelling the specific activity of the water-soluble glucan fraction rose at a rate which was at least twice as fast as that of the alkali-insoluble glucan fraction. On the other hand, the specific activity of total glucan and of the alkali-soluble glucan fraction rose at an intermediate rate. Assuming a common pool of precursors for glucan synthesis and steadystate conditions, this can only be explained by a continuous loss of (non-radioactive) glucan from the water-soluble fraction and a continuous addition of previously (non-radioactive) synthesized glucan to the alkali-insoluble glucan during the labelling period. In agreement with this, the specific radioactivity of the alkali-insoluble glucan initially continued to increase even during the chase. Therefore, the simplest explanation is that a large part, if not all, of the insoluble glucan was originally synthesized as a water-soluble glucan which was subsequently rendered alkali-insoluble.

\section{Localization of newly synthesized glucans in the growing hyphal wall}

Wall glucans are predominantly synthesized at the hyphal apex (Gooday, 1971), hence it was of interest to examine the distribution of the various newly synthesized glucan fractions in this region. Since we wanted to retain all glucans while removing most of the cytoplasm before autoradiography, we first treated the hyphae with alkali in ethanol, as done by earlier investigators (Bartnicki-Garcia \& Lippman, 1969), before proceeding with the extractions. Preliminary experiments demonstrated that glucan was not removed under these conditions. As in the previous experiment, actively growing basidiospore germlings $(16 \mathrm{~h})$ were labelled, but in this case with $\left[{ }^{3} \mathrm{H}\right] \mathrm{glucose}$ and only for $10 \mathrm{~min}$. The radioactivity was then chased and samples were taken 15 and 45 min after the chase. After extraction and autoradiography, grains were counted in 40 hyphae which gave grains and which were selected at random.

The wall glucans were predominantly synthesized at the apex and during the chase period these glucans moved to subapical areas at a rate of about $7 \mu \mathrm{m} \mathrm{h}^{-1}$ (Fig. $2 a$ ). In the zero-time sample most of the label was located somewhat behind the very tip of the apex, probably because this sample was taken immediately after the chase procedure which took about 3 min and which allowed for a very short period of growth in non-radioactive medium. The chase procedure obviously had adverse effects on growth because about half of the labelled hyphae failed to continue growth after the chase (these could be traced after $45 \mathrm{~min}$ since they showed no displacement of label). This may also explain the difference in growth rate measured in this experiment $\left(7.01 \mu \mathrm{m} \mathrm{h}^{-1}\right)$ and the previous experiment $\left(3.68 \mu \mathrm{m} \mathrm{h}^{-1}\right)$. In the latter no distinction could be made between non-growing and growing hyphae and the figure represents the average increase in length of a total hyphal population.

By subtraction, data were obtained for the distribution of label extracted with hot water (Fig. $2 b$ ) and by a subsequent extraction with alkali (Fig. $2 c$ ). The residue shows the label in the alkali-insoluble glucan (Fig. $2 d$ ). A comparison of the histograms shows that after $10 \mathrm{~min}$ labelling with $\left[{ }^{3} \mathrm{H}\right]$ glucose, most of the label at the extreme tip was present in a water-soluble and alkali-soluble form, with very little alkali-insoluble glucan present in this area. In accordance with the previous experiment, the total amount of radioactive alkali-insoluble glucan was low but increased during growth in non-radioactive medium. Apparently, this occurred at the expense of water-soluble glucan which virtually disappeared during the chase period. However, this experiment also shows that the conversion of water-soluble glucan into alkali-insoluble glucan occurred while the newly synthesized glucan in the growing hyphae moved from the extreme tip to more subapical parts. Although this transformation proceeded over a considerable length of time, examination of the zero-time histograms indicates that this process 


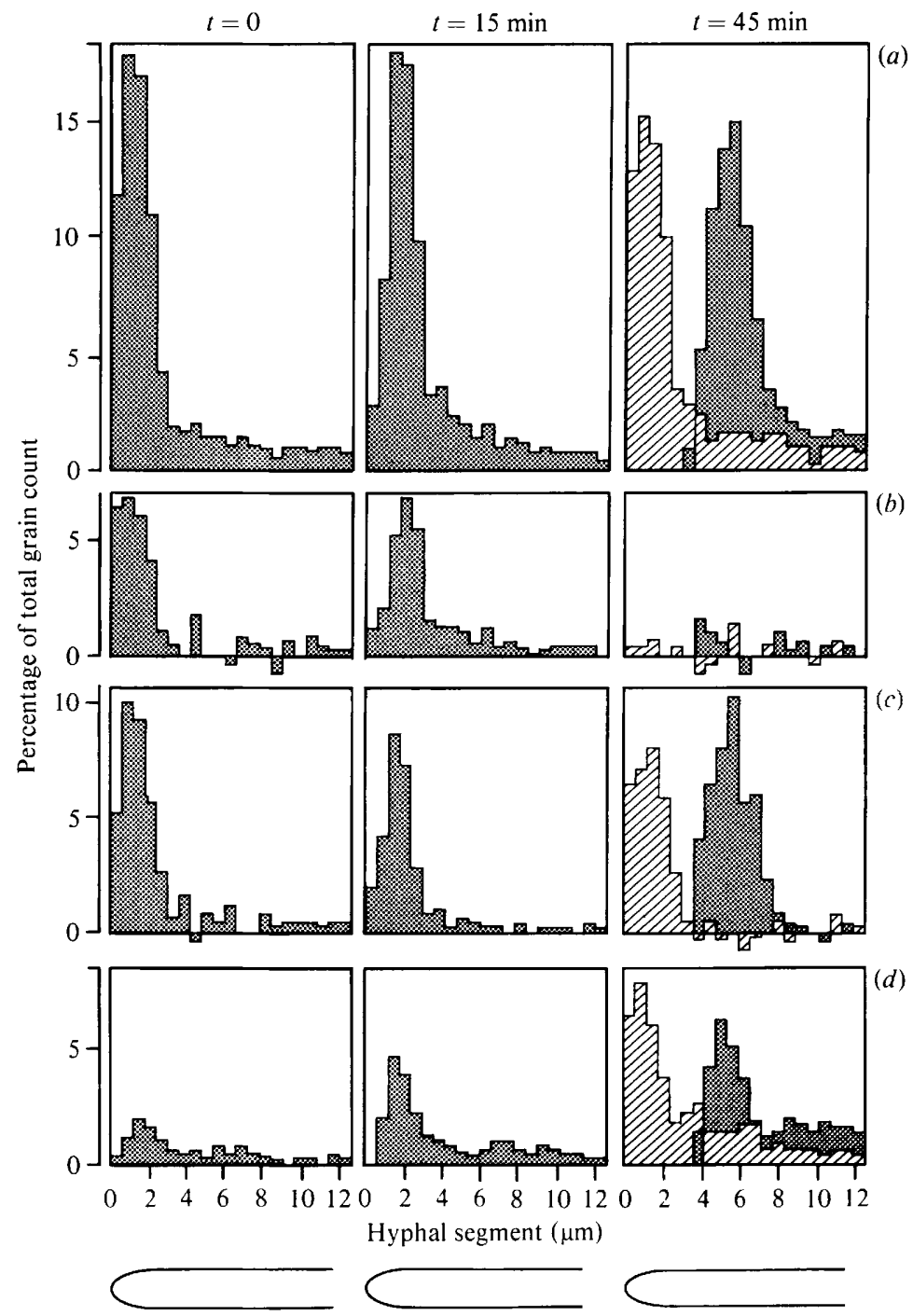

Fig. 2. Sites of glucan incorporation in growing hyphae of $S$. commune. Minimal medium ( $2 \mathrm{ml}$, containing $5 \mathrm{mg}$ glucose $\mathrm{ml}^{-1}$ ) was inoculated with $16 \times 10^{7}$ basidiospores. After $16 \mathrm{~h}$ growth, a pulse of $0.2 \mathrm{mCi}\left[6-{ }^{3} \mathrm{H}\right]$ glucose was given for $10 \mathrm{~min}$. The radioactivity was then chased and incubation continued in non-radioactive minimal medium. Samples of $0.5 \mathrm{ml}$ were taken immediately after the chase $(t=0)$, at $15 \mathrm{~min}(t=15)$ and at $45 \mathrm{~min}(t=45)$. Samples were treated and autoradiograms prepared as described in Methods. The grains were counted in segments $(0 \cdot 6 \mu \mathrm{m})$ of the hyphae starting at the tip. Each column represents the percentage of the total grain count in a segment of $12 \mu \mathrm{m}$, averaged for 40 hyphae. (a) Total grains; $(b)$ grains disappearing after extraction with water at $100^{\circ} \mathrm{C}$; (c) grains disappearing after extraction with $1 \mathrm{M}-\mathrm{KOH}$ at $60^{\circ} \mathrm{C} ;(d)$ grains remaining after extraction with $1 \mathrm{M}-\mathrm{KOH}$. The $t=45 \mathrm{~min}$ histograms show two populations of labelled hyphae: one population in which the label had moved to subapical parts (stippled area), and another in which the label stayed at the apex during the chase (hatched area). At the bottom of the histograms the average shape of a hypha is depicted. The average diameter and the length of the extension zone were both $1.8 \mu \mathrm{m}$.

was already underway in the extension zone, i.e. that part of the hyphae where the maximal diameter has not yet been attained.

As noted above, about half of the hyphae failed to continue growth after the chase. In the hyphae sampled after $15 \mathrm{~min}$, this population could not be well distinguished and therefore the data obtained for this sampling time pertain to both growing and non-growing tips. However, 


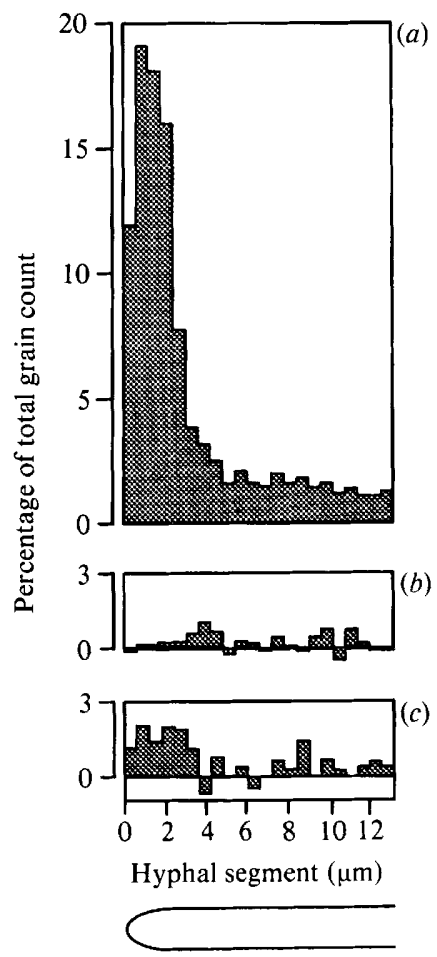

Fig. 3. Site of chitin incorporation in growing hyphae. The experiment was performed in the same way as described in the legend to Fig. 2, except that $N$-acetyl[ $\left.6-{ }^{3} \mathrm{H}\right]$ glucosamine was used as the radioactive precursor. (a) Total grains; (b) grains disappearing after extraction with water at $100{ }^{\circ} \mathrm{C} ;(c)$ grains disappearing after extraction with $1 \mathrm{M}-\mathrm{KOH}$ at $60^{\circ} \mathrm{C}$. The average shape of a hypha is also depicted (see Fig. 2 legend for measurements).

after $45 \mathrm{~min}$ the two populations could be clearly distinguished, and the data (Fig. 2, hatched areas) show that in these non-growing tips the water-soluble glucan synthesized initially was also converted into alkali-insoluble glucan. Apparently the conversion was not dependent on growth per se and was only time-dependent.

Because of the low chitin/glucan ratios in these walls (Sietsma \& Wessels, 1977) grains due to newly synthesized chitin did not significantly contribute to the numbers of grains counted. To visualize the synthesis of chitin, the same experiment was performed, but in this case the hyphae were labelled with $\mathrm{N}$-acetyl[ $\left[{ }^{3} \mathrm{H}\right]$ glucosamine. As expected, radioactivity was incorporated preferentially at the tip, but little water-soluble or alkali-soluble labelled material could be detected (Fig. 3). Apparently, the precursor was instantaneously incorporated into an alkaliinsoluble polymer.

\section{Mechanical fragility of growing hyphal tips}

In preliminary experiments designed to obtain clean wall preparations for autoradiography, labelled hyphae were broken in an X-press and washed to remove the cytoplasm. Surprisingly, few labelled tips could be observed, irrespective of labelling with $\left[{ }^{3} \mathrm{H}\right]$ glucose or $\mathrm{N}$ acetyl $\left[{ }^{3} \mathrm{H}\right]$ glucosamine. In the latter case, grains were detected but these were dispersed throughout the preparation. In contrast, after a chase and passage through an X-press, grains were readily detected either at the tip or in subapical parts of the hyphae.

To obtain more quantitative information about these phenomena, hyphae were labelled for 30 min with either $\left[{ }^{14} \mathrm{C}\right]$ glucose or $\mathrm{N}$-acetyl $\left[{ }^{14} \mathrm{C}\right]$ glucosamine, then briefly washed and broken in an X-press. The fragmented material was centrifuged at $3000 \mathrm{~g}$ for $10 \mathrm{~min}$ to obtain a wall pellet and then methanol was added to both the pellet and the supernatant to give a final concentration 


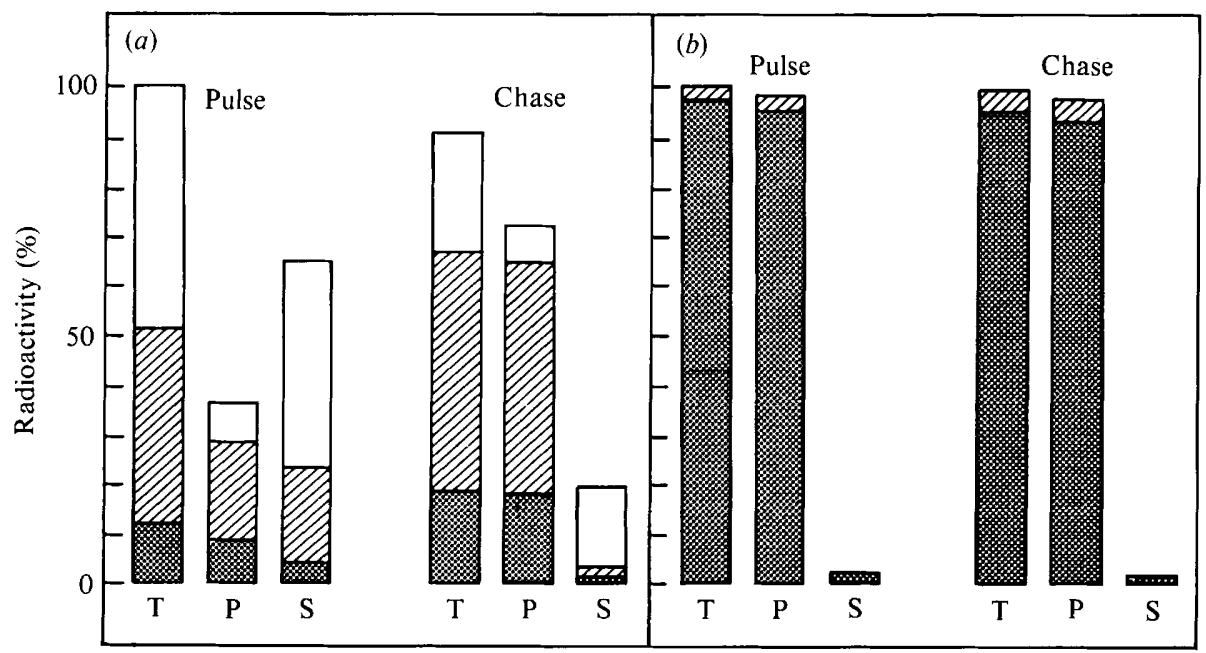

Fig. 4. The distribution of label between the $3000 \mathrm{~g}$ pellet (cell wall fraction) and supernatant during pulse-chase conditions. Mycelium was grown for $16 \mathrm{~h}$, after which a pulse of $(a) 50 \mu \mathrm{Ci} \mathrm{ml}^{-1}$ [U$\left.{ }^{14} \mathrm{C}\right]$ glucose, or $(b) 50 \mu \mathrm{Ci} \mathrm{ml}{ }^{-1} \mathrm{~N}$-acetyl[U-14 $\left.\mathrm{C}\right]$ glucosamine was given for $30 \mathrm{~min}$. Half of the culture was then disrupted; from the other half the radioactivity was chased and cultivation continued for $60 \mathrm{~min}$ in non-radioactive medium before the hyphae were disrupted. Both homogenates were centrifuged at $3000 \mathrm{~g}, 4^{\circ} \mathrm{C}$ for $10 \mathrm{~min}$ and methanol was added to both pellets and supernatants to give a final concentration of $66 \%$. The precipitates were extracted with $1 \mathrm{M}-\mathrm{KOH}$ in $66 \%$ ethanol at $60{ }^{\circ} \mathrm{C}$, washed with $66 \%$ ethanol, and extracted successively with water at $100{ }^{\circ} \mathrm{C}$ and $1 \mathrm{M}-\mathrm{KOH}$ at $60{ }^{\circ} \mathrm{C}$. After each extraction procedure a sample was taken and the radioactivity counted using the liquid scintillation method. Open areas, hot-water-soluble material; hatched areas, alkali-soluble material; stippled areas, alkali-insoluble material. T, Total fraction; P, $3000 \mathrm{~g}$ pellet; $\mathrm{S}, 3000 \mathrm{~g}$ supernatant.

of $66 \%$. The precipitates were washed with $66 \%$ methanol, treated with $1 \mathrm{M}-\mathrm{KOH}$ in ethanol and then fractionated into water-soluble, alkali-soluble and alkali-insoluble material as before. The results in Fig. 4 show that the same pattern of conversion as noted in the previous experiments can be seen in the total homogenate, i.e. water-soluble glucan was converted into alkali-insoluble glucan but chitin was alkali-insoluble from the beginning. Whereas all the newly synthesized chitin sedimented with the walls at $3000 \mathrm{~g}$, this was not the case with the newly synthesized glucans. Most of the water-soluble glucan, and half of the alkali-soluble glucan, stayed in the supernatant. Only the alkali-insoluble glucan appeared predominantly in the wall fraction. However, after the chase only residual radioactive water-soluble glucan stayed in the supernatant fraction.

Combining the autoradiographic data with the results of the fractionation, it appears that the shearing forces generated during passage through the X-press disrupted the growing apices, but not those that had stopped growing.

\section{DISCUSSION}

Chemical and structural information on hyphal walls is usually obtained from whole-wall preparations in which the wall materials derived from hyphal tips constitute only a minor fraction. Although hyphae grow by apical extension, and autoradiography shows a steep increase of synthesis of wall materials at the apex (Bartnicki-Garcia \& Lippman, 1969; Gooday, 1971), there is usually a low level of precursor incorporation detectable in the subapical regions of the hyphae, especially when $\left[{ }^{3} \mathrm{H}\right]$ glucose is used as the wall precursor (Gooday, 1971). Because of the large area involved, the total amount of wall material synthesized subapically may be considerable and may even predominate in wall preparations made from hyphae which have undergone secondary wall thickening. As shown in the present paper, the wall materials may also be modified after deposition in the wall. For these reasons it is very difficult to apply 
chemical information obtained from whole-wall preparations to the nature of the wall components as they are synthesized at the hyphal apex.

Whole-wall preparations of $S$. commune, obtained from 5-d-old cultures, contain as major components, chitin $(10 \%)$ and $(1 \rightarrow 3)-\beta /(1 \rightarrow 6)-\beta$-D-glucan $(39 \%)$ which are covalently linked in an alkali-insoluble complex, and alkali-soluble (1-3)- $\alpha$-D-glucan $(21.8 \%$ ) (Sietsma \& Wessels, 1977 , 1979). As shown in the present study, the alkali-insoluble glucan complex is not present at the very tip of the hyphal apex but water-soluble and alkali-soluble glucan predominate in this region. As to the glycosidic linkages in these glucans, at present it can only be said that about half of the water-soluble glucan can be degraded by exo-( $1 \rightarrow 3)-\beta$-glucanase, giving glucose but no gentiobiose as product (A. S. M. Sonnenberg, unpublished observations). This indicates the presence of a $(1 \rightarrow 3)-\beta$-glucan without $(1 \rightarrow 6)$ - $\beta$-linked glucose branches. In addition, about $30 \%$ can be degraded by $\alpha$-amylase, indicating the presence of contaminating glycogen. Apart from $(1 \rightarrow 3)$ - $\beta$-glucan, glycogen-like material was also found among the water-soluble glucans synthesized in regenerating protoplasts of $S$. commune (Sonnenberg et al., 1982). In these regenerating protoplasts it was found that the newly synthesized alkali-soluble glucan fraction also contained a small amount of $(1 \rightarrow 3)$ - $\beta$-glucan in addition to $(1 \rightarrow 3)$ - $\alpha$-glucan and this may similarly apply to the alkali-soluble glucan synthesized at the hyphal apex. On the other hand, both in the protoplasts and at the hyphal apex, $N$-acetylglucosamine is incorporated immediately into an alkali-insoluble homopolymer which by definition is called chitin. However, this does not mean that this polymer immediately represents microcrystalline microfibrillar chitin. Others (Gooday \& Trinci, 1980; Lopez-Romero et al., 1982; Schneider \& Seaman, 1982) have shown that nascent chitin is particularly sensitive to chitinase and acid, and the chitin at the apex may thus be present in a rather amorphous condition. This means that at this stage of wall assembly the chitin chains may still be available for cross-linking with other polymers.

Irrespective of the uncertainties regarding the exact chemical nature of the hot-water-soluble glucans synthesized at the apex, the results presented in this paper clearly show that a major fraction of these soluble glucans is gradually turned into an alkali-insoluble form. In growing hyphae this process starts just under the extreme tip and continues subapically. The process is sustained because in the growing hyphae hot-water-soluble glucan is continuously deposited in the wall at the apex. When growth ceases, however, all the $\beta$-glucan at the apex is gradually converted into an alkali-insoluble form. As previously suggested for regenerating protoplasts (Sonnenberg et al., 1982), we hypothesize that at the hyphal apex $(1 \rightarrow 3)-\beta$-glucan and chitin are synthesized as separate wall components which are then gradually cross-linked in the wall, producing an alkali-insoluble $\beta$-glucan-chitin complex. The model given in Fig. 5 assumes two wall components, chitin and $\beta$-glucan, being singularly inserted in the growing wall at the apex so that the wall is initially plastic and can yield to the turgor pressure. These two components then become progressively cross-linked by enzymes in the wall, increasing the rigidity of the wall until it no longer yields to the turgor pressure. At this point the maximum diameter of the hypha would be attained. The model assumes that cross-linking is sufficiently slow to allow for expansion of the apex. In the absence of growth, however, the cross-linking would proceed over the whole apex, producing a rigid wall which would no longer yield to the turgor pressure. A correlation between the assumed existence of non-cross-linked chitin and $\beta$-glucan chains at the apex and the mechanical properties of the wall in this region is clearly suggested by the fact that high shearing forces, as generated during passage through an X-press, remove these polymers from growing apices, but not from non-growing apices and subapical regions where they are believed to be cross-linked into a highly insoluble shearing-resistant complex.

The model is essentially similar to that advanced by Robertson (1958) on the basis of simple growth experiments. Hyphal extension growth was interpreted in terms of a newly formed plastic wall extruding under turgor thrust and then developing rigidity. He also noted that by arresting extension, a rigidity developed in the apex which depended on the duration of arrestment. An apex of Fusarium oxysporum arrested for longer than $40 \mathrm{~s}$ became rigid over the entire apex and new growth took place by subapical branching. The notion that the newly 


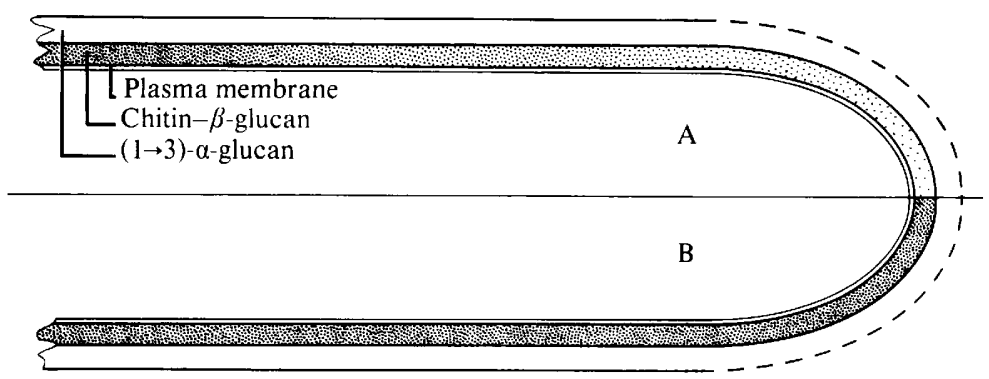

Fig. 5. A model depicting the extent of cross-linking between $\beta$-glucan and chitin in the apical region of growing (A) and non-growing (B) hyphae. The density of stippling reflects the degree of cross-linking.

formed wall is plastic until made rigid has also been implicit in mathematical analyses as presented by Da Riva Ricci \& Kendrick (1972) and Green (1974). The new evidence presented in this paper suggests a molecular mechanism by which this transition from plasticity towards rigidity develops.

With regard to the mechanism involved, our model seems to contrast with that advanced by Bartnicki-Garcia (1973) in which it is assumed that the wall at the apex is rigid until loosened by hydrolytic enzymes. In this model extension growth would result from a delicate balance between synthesis and lysis of wall components; lysis producing plasticity and allowing for insertion of new polysaccharide chains. The evidence for the role of lytic enzymes, which is largely circumstantial, has been discussed by Gooday (1978). In addition, we would like to point to the difficulty of conceiving a mechanism for the precise regulations of the activity of lytic enzymes in the wall outside the plasma membrane. As for the evidence presented in favour of a role for lytic enzymes, at least some of it can also be easily interpreted in terms of the present model. For instance, Bartnicki-Garcia \& Lippman (1972) interpreted the bursting of hyphal tips after treatment of hyphae with polyoxin $\mathrm{D}$ as being due to continuing lysis after arrestment of synthesis of chitin by the antibiotic. The present model would also predict bursting of the apex because one of the components of the cross-linked chitin-glucan complex would no longer be formed.

It is important to stress that notwithstanding the assumed absence of a major role for lytic enzymes in the steady-state process of apical extension growth, lytic enzymes probably still play a very important role in organizing apical growth centres in rigidified areas of the wall, e.g. in branch formation.

An interesting inference from the model of hyphal tip growth as presented here is that one would expect to see structural differences between apical and subapical wall areas of growing hyphae, particularly after extractions with hot water and alkali. Except for a report by Marchant (1966) we are not aware of studies documenting such differences. On the other hand the model would also predict the absence of structural differences between apical and subapical areas in non-growing hyphae. As shown by microautoradiography, the percentage of non-growing tips can be considerable in growing cultures and these tips can be expected to be less fragile and more readily preserved for electron microscopy than growing tips. A careful study investigating the validity of this argument should therefore be undertaken. Such a study should also take into account the fact that chemical treatment of the walls may introduce structural features not present in the native walls, as discussed elsewhere (Wessels \& Sietsma, 1981).

The skilful technical assistance of Mrs B. Lenting-Kuipers was very much appreciated. Part of this study was supported by the Foundation for Fundamental Biological Research (BION), which is subsidized by the Netherlands Organization for the Advancement of Pure Research (ZWO). 


\section{REFERENCES}

BARTNICKI-GARCIA, S. (1973). Fundamental aspects of hyphal morphogenesis. Symposia of the Society for General Microbiology 23, 245-267.

Bartnicki-Garcia, S. \& Lippman, E. (1969). Fungal morphogenesis: cell wall construction in Mucor rouxii. Science 165, 302-304.

BARTNICKI-GARCIA, S. \& LipPMAN, E. (1972). Inhibition of Mucor rouxii by Polyoxin D: effects on chitin synthetase and morphological development. Journal of General Microbiology 71, 301-309.

Da Riva Ricci, D. \& Kendrick, B. (1972). Computer modelling of hyphal tip growth in fungi. Canadian Journal of Botany 50, 2455-2462.

Dons, J. J. M., VRIES, O. M. H. DE \& Wessels, J. G. H. (1979). Characterisation of the genome of the basidiomycete Schizophyllum commune. Biochimica et biophysica acta 563, 100-112.

FAIRBAIRN, N. J. (1953). A modified anthrone reagent. Chemistry and Industry 72, 86.

Gooday, G. W. (1971). An autoradiographic study of hyphal growth of some fungi. Journal of General Microbiology 67, 125-133.

Gooday, G. W. (1978). The enzymology of hyphal growth. In The Filamentous Fungi, vol. 3, pp. 51-77. Edited by J. E. Smith \& D. R. Berry. London: Edward Arnold.

Gooday, G. W. \& Trinci, A. J. P. (1980). Wall structure and biosynthesis in fungi. Symposia of the Society for General Microbiology 30, 207-251.

Green, P. B. (1974). Morphogenesis of the cell and organ axis. Biophysical models. Brookhaven Symposia in Biology 25, 166-190.

KocH, A. L. (1982). The shape of the hyphal tips of fungi. Journal of General Microbiology 128, 947-951.

LOPEZ-Romero, E., RUIZ-HERRERA, J. \& BARTNICKIGARCIA, S. (1982). The inhibitory protein of chitin synthetase from Mucor rouxii is a chitinase. Biochimica et biophysica acta 702, 233-236.

MARChANT, R. (1966). Wall structure and spore germination in Fusarium culmorum. Annals of Botany 30, $821-830$.

ROBERTSON, N. F. (1958). Observations of the effect of water on the hyphal apices of Fusarium oxysporum. Annals of Botany 22, 159-173.

ROBERTSON, N. F. (1968). The growth process in fungi. Annual Review of Phytopathology 6, 115-136.

RogERs, A. W. (1969). Techniques of Autoradiography, 1st edn, pp. 210-211. Amsterdam: Elsevier Publishing Company.

Schneider, E. F. \& Seaman, W. L. (1982). Structure of chitin in the cell walls of newly formed and mature conidia of Fusarium sulphureum. Canadian Journal of Microbiology 28, 531-535.

Sietsma, J. H. \& Wessels, J. G. H. (1977). Chemical analysis of the hyphal wall of Schizophyllum commune. Biochimica et biophysica acta 496, 225-239.

Sietsma, J. H. \& Wessels, J. G. H. (1979). Evidence for covalent linkages between chitin and $\beta$-glucan in a fungal wall. Journal of General Microbiology 114, 99108.

Sietsma, J. H. \& Wessels, J. G. H. (1981). Solubility of $(1 \rightarrow 3)-\beta-D /(1 \rightarrow 6)-\beta$-D-glucan in fungal walls: importance of presumed linkage between glucan and chitin. Journal of General Microbiology 125, 209-212.

Sonnenberg, A. S. M., Sietsma, J. H. \& Wessels, J. G. H. (1982). Biosynthesis of alkali-insoluble cellwall glucan in Schizophyllum commune protoplasts. Journal of General Microbiology 128, 2667-2674.

Trinci, A. J. P. \& Collinge, A. (1975). Hyphal wall growth in Neurospora crassa and Geotrichum candidum. Journal of General Microbiology 91, 355-361.

Trinci, A. J. P. \& Saunders, P. T. (1977). Tip growth of fungal hyphae. Journal of General Microbiology 103, 243-248.

Wessels, J. G. H. \& Sietsma, J. H. (1981). Fungal cell walls: a survey. In Encyclopedia of Plant Physiology vol. 13B, pp. 352-394. Edited by W. Tanner \& F. A. Loewus. Heidelberg: Springer-Verlag. 